\title{
Fungal Community Diversity of a Heavy Metal Contaminated Soils Revealed by Metagenomics
}

Michel Rodrigo Zambrano Passarini ( $\nabla$ michel.passarini@unila.edu.br)

Universidade Federal da Integracao Latino-Americana https://orcid.org/0000-0002-8614-1896

Júlia Ronzella Ottoni

Universidade Federal da Integração Latino-Americana

Paulo Emílio Santos Costa

Regional University of Cariri

Denise Cavalvante Hissa

Federal University of Ceara

Raul Maia Falcão

Federal University of Pernambuco

Vânia Maria Maciel Melo

Federal University of Ceara

Valdir Queiroz Balbino

Federal University of Pernambuco

Luiz Alberto Ribeiro Mendonça

Federal University of Cariri

Maria Gorethe de Sousa Lima

Federal University of Cariri

Henrique Douglas Melo Coutinho

Regional University of Cariri

Leandro Costa Lima Verde

Regional University of Cariri

\section{Research Article}

Keywords: omics technique, bioremediation, hazardous wastes, uncultured fungal, heavy metal metabolism, heavy metal tolerance

Posted Date: August 4th, 2021

DOl: https://doi.org/10.21203/rs.3.rs-730302/v1

License: (9) This work is licensed under a Creative Commons Attribution 4.0 International License. 
Version of Record: A version of this preprint was published at Archives of Microbiology on April 12th, 2022. See the published version at https://doi.org/10.1007/s00203-022-02860-7. 


\section{Abstract}

The inappropriate disposal of toxic compounds generated by industrial activity has been impacting to the environment considerably. Microbial communities inhabiting contaminated sites may represent interesting ecological alternatives for the decontamination of environments. The present work aimed to investigate the fungal diversity inhabiting sediments from industrial waste containing heavy metals by using metagenomic approach. A total of twelve fungal orders were retrieved from datasets and, at phylum level, Ascomycota was the most abundant, followed by Basidiomycota, Chytridiomycota and Blastocladiomycota. Higher abundance of sequences was encountered within the less contaminated site, while the lower abundance was found in the sample with the higher contamination with lead. Gene sequences related to DNA repair and heavy metals biosorption processes were found in the four samples analyzed. The genera Aspergillus and Chaetomium, and Saccharomycetales order were highly present within all samples, showing their potential to be used for bioremediation studies. The present work demonstrated the importance of using the metagenomic approach to understand the dynamics of fungal communities and their behavior under heavy metal contamination, aiming the use in bioremediation processes of environments contaminated with heavy metals.

\section{Introduction}

With the increase of human industrial activities, a major impact on the environment has been occurring through the disposal of waste containing heavy metals. Industrial wastewater and sewage sludge mainly from electroplating, leather tanning, wood preservation, pulp processing and steel manufacturing are the main sources of contamination of water bodies and soil by heavy metals which may adversely affect soil health, fresh water resources and groundwater quality (Iram et al. 2012). These industrial processes may generate residues containing organic matter and a wide variety of heavy metals. The prolonged exposure to excessive heavy metals concentration from industrial effluent may be highly harmful for both animal and human health, and has been associated to the occurrence of carcinogenesis, respiratory cancer, mutagenesis and cardiovascular and gastrointestinal diseases (Ahmad 2005; Akhtar et al. 2013; Woldeamanuale 2017).

Heavy metals are divided into essentials, including copper, nickel, zinc and iron which are necessary to perform the proper functions of all biological systems, and nonessential, such as lead, mercury and cadmium. However, in high concentrations, both categories may be toxic to microorganisms (Dopson et al. 2003; Rasool and Irum 2014; Woldeamanuale 2017).

Microbial communities present in heavy metals contaminated environments have developed detoxification strategies such as bioaccumulation, in order to protect the microbial cell wall, in an attempt to survive in these adverse environments (Dopson et al. 2003; Fidalgo 2011; Qayyum et al. 2016). Interaction between heavy metals and microbial communities can be classified into different categories such as extracellular, exocellular and intracellular, in which microbial cells can mobilize, immobilize, transform, precipitate, accumulate, coordinate, exchange and absorb the metal, as well as forming 
complexes (Joshi 2014). According to Iram and co-workers (2012), melanins (a dark pigment) located in the fungal cell wall and also an extracellular polymer, have the ability to reduce the toxic effect of heavy metals. Due to this property, fungi may grow in contaminated environments, binding with heavy metals and accumulating these substances in their cells, representing an efficient alternative in the removal of these toxic compounds in waste waters and other terrestrial and aquatic sites in natural environments. These characteristics demonstrate that heavy metal resistant microorganisms may also be applied as biological monitors or bioindicators of environmental contamination (Iram et al. 2012).

Several works have been developed to investigate the sensitivity or resistance of fungi to heavy metals from different habitats and their mechanisms of adaptation to these toxic substances. In the work carried out by Joshi (2014), fungi isolates derived from effluent samples collected from contaminated sites in India were screened for heavy metals resistance for lead (Pb), nickel (Ni), cobalt (Co), chrome (Cr), copper $(\mathrm{Cu})$, manganese $(\mathrm{Mg})$ and zinc $(\mathrm{Zn})$. The author found one isolate belonging to Neurospora genera which showed tolerance to manganese $\left(60 \mathrm{mg} \mathrm{mL}^{-1}\right)$, copper $\left(5 \mathrm{mg} \mathrm{mL}^{-1}\right)$, cobalt $\left(5 \mathrm{mg} \mathrm{mL}^{-1}\right)$, lead $(4.5$ $\left.\mathrm{mg} \mathrm{mL}^{-1}\right)$, nickel $\left(6 \mathrm{mg} \mathrm{mL}^{-1}\right)$ and chrome $\left(3.9 \mathrm{mg} \mathrm{mL}^{-1}\right)$. The fungal diversity and tolerance to heavy metals were studied by Iram et al. (2012), who found three Aspergillus isolates able to tolerate contamination by heavy metals including $\mathrm{Cd}, \mathrm{Cu}, \mathrm{Ni}$ and $\mathrm{Zn}$ at concentrations ranging from 1 to 40 $\mathrm{mg} / \mathrm{kg}$. The resistant filamentous fungi found by the authors were isolated from soil samples collected from agricultural soils irrigated with waste from industries, sewage systems and mine. Iskandar et al. (2011) screened 41 isolates of filamentous fungi obtained from the sediment of the Langat River, Selangor, Malaysia for their tolerance and capability to uptaking copper and lead. In this work, three Aspergillus, one Trichoderma and three Penicillium strains were able to survive at $1000 \mathrm{mg} \mathrm{L}^{-1}$ of copper. With regard to lead, only $A$. niger survived at $5000 \mathrm{mg} \mathrm{L}^{-1}$ concentration. Furthermore, $A$. niger, $P$. simplicissimum and $T$. asperellum showed a promising biosorption of copper and lead in aqueous solution.

The importance of exploring the metagenomic approach to access information from the uncultured majority of microbial communities present in the most diverse environments has been demonstrated by several researches (Barone et al. 2014; Beale et al. 2015; Hiraoka et al. 2016: Mosier et al. 2016). As the methods used in metagenomics have evolved during time, the use of massive sequencing of the microbial community contained in a sample, represent an optimum tool to recover information from those communities. Sequencing technologies along with statistics platforms have been providing robust data from different samples, including heavy metal contaminated sites, which nowadays may provide information from non-cultivable microorganisms (Donati 2018). Even with such tools available, the knowledge around fungal communities diversity and their ability to metabolize or adsorb heavy metals from contaminated sediments by using information provided by metagenomics accessed through Next Generation Sequencing (NGS) remains under-explored. The metagenomic datasets have been the object of researches that aim to identify the mechanisms of adaptation of the microbial communities to inhospitable environments (Costa et al. 2015), reached due to the metabolic flexibility of these organisms 
inherited from specific functional genes including heavy metal resistance genes in bacterial communities (Feng et al. 2018; Hiraoka et al. 2016; Yin et al. 2015; Zhang et al. 2016).

Current knowledge about mechanisms of metal resistance is mostly based on cultured microorganisms, which limits the information as traditional microbiological techniques of isolation and culture recover a small proportion ( 0,1 to $1 \%$ ) of the microorganisms in soil samples (Feng et al. 2018). It is important to notice that the metagenomic approach and bioinformatics analyses go together (Hiraoka et al. 2016), and that those are current the most efficient tools to access the information derived from less abundant species within the environment, which may have important role in the dynamic of the microbial communities adaptation processes (Donati 2018).

Hemme and co-workers (2010) analyzed the metagenome of samples from acidic groundwater ( $\mathrm{pH} 3-7)$ highly contaminated with heavy metals such as uranium and technetium, as well as nitric and organic acids. The communities present in the environment were exposed to these conditions for approximately 50 years and the authors verified that such conditions resulted in reduction of microbial species and allelic diversity, as well as significant loss of metabolic diversity. Zhao et al. (2015) investigated the genes associated with $\mathrm{Cd}$ stress in the endophytic fungal $\mathrm{Cd}$-tolerant strain Exophiala pisciphila isolated from the roots of the plant Arundinella bengalensis. Using the RNA-seq approach, authors found 228 unigenes involved in different pathways associated with Cd-tolerance. Lehembre et al. (2013) performed a study by screening soil eukaryotic metatranscriptomes containing RNA from the main eukaryotic phyla organisms. The mRNAs were converted into cDNAs and, after screening, 35 were selected for their ability to recover yeasts mutants phenotypes sensitive to metal (Cd or Zn). In this work, among several environmental genes related to eukaryotic organisms, 2 genes related to heavy metal resistance were found, a metallothionein from Basidiomycota phylum and a clone of polyubiquitin from Fungi taxonomic group.

Methallothioneins are peptides related to chelation and chelate transport, binding mostly with $\mathrm{Cd}$, $\mathrm{Cu}$ and $\mathrm{Zn}$; ubiquitins mark unwanted proteins, such metal-demaged enzymes. The authors concluded that these genes categories may be used to probe new pathways involved in homeostasis and resistance to several heavy metals (Gube 2016; Lehembre et al. 2013).

In this way, the present work aimed to perform a comprehensive analysis of the taxonomic and functional composition of fungal communities present in sediment samples contaminated with heavy metals of Macacos Creek in the municipality of northern Juazeiro, Ceará, Brazil, through the metagenomics approach.

\section{Material And Methods}

\section{Sampling}

Samples were collected from the edge of four different creeks in the municipality of northern Juazeiro, Ceará, Brazil. In order to explore the microbial community composition and function, approximately $150 \mathrm{~g}$ of soil were collected in the superficial layers, in the 0 to $20 \mathrm{~cm}$ profile, from areas adjacent to the creek, 
using a non-metal tool. The chosen depth of the layer, of up to $20 \mathrm{~cm}$, contains the highest levels of chemical elements and organic matter, as well as the interaction between them, according to Aguiar (2007). The samples were properly conditioned and sent to the Laboratory of Sanitation of the Federal University of Cariri (UFCA).

Soil from four different sites was sampled, including: a) Grangeiro River (RG - control), located in the municipality of Crato - CE (7० 28' 02,27" S and 39ه 43' 81.50" W) - reserved area where water is less likely to be contaminated by metals; $b$ ) Salesianoo Creek (RS) - in the municipality of Juazeiro do Norte - CE ( $7^{\circ}$ $21^{\prime} 16,25^{\prime \prime} \mathrm{S}$ and $39^{\circ} 19^{\prime} 31,15^{\circ} \mathrm{W}$ ) which is highly contaminated by heavy metals; mainly $\mathrm{Cr}$ and $\mathrm{Pb} ; \mathrm{c}$ ) APUC Lagoon (RA - $7^{\circ} 14^{\prime} 45,02^{\prime \prime} \mathrm{S}$ and $39^{\circ} 18^{\prime} 58^{\prime \prime} \mathrm{W}$ ), with moderate contamination of all heavy metals; and d) Macacos Creek (RM - $7^{\circ} 21^{\prime} 29,77^{\prime \prime}$ and 39ه 30'38,83" W) containing great contamination of all heavy metals; especially $\mathrm{Cu}, \mathrm{Ni}$ and $\mathrm{Zn}$ (Figure 1). The Macacos Creek is closely located to manufacturing industries that work with corrosive, flammable and toxic products, such as jewelry, aluminum and leather dyeing factories. Soils were sampled in triplicate at a distance of one meter from the margin of sampling sites at a depth of $5 \mathrm{~cm}$ by using polyvinyl chloride (PVC) pipes of $10 \mathrm{~cm}$ diameter previously sterilized. After sampling, the material was taken to the laboratory and maintained at $4{ }^{\circ} \mathrm{C}$ until processing to perform the analyzes.

\section{Soil Analysis for Heavy Metals}

The samples were dried at room temperature and particles were manually reduced to a fine powder, which were sifted to obtain a fine fraction $(<0.074 \mathrm{~mm})$, required for chemical analysis. For the determination of the heavy metals, the methodology of digestion in microwaves in the presence of concentrated nitric acid was used, followed by reading in Inductively Coupled Plasma-Optical Emission Spectroscopy - ICP/OES (method 3051-16), recommended by United States Environmental Protection Agency (US EPA, 1994).

\section{DNA extraction}

Total soil community DNA was extracted from $0.25 \mathrm{~g}$ of each soil sample by using the MoBio PowerSoil DNA Isolation Kit (MoBio, Carlsbad, CA, USA) according to the manufacturer's instructions. Purity of the extracted DNA was checked using a Nanodrop ND-1000 spectrophotometer (Nanodrop Technologies, Wilmington, DE, USA) and DNA concentration was determined using Qubit ${ }^{\circledR} 2.0$ fluorometer (Invitrogen, Carlsbad, CA, USA). Integrity of the DNA was confirmed by electrophoresis in a $0.8 \%$ agarose gel. All DNA samples were stored at $-20^{\circ} \mathrm{C}$ until downstream analyses.

\section{Metagenomic DNA sequencing and in silico data analysis}

Shotgun metagenome libraries were constructed by using a Nextera XT DNA Sample Preparation Kit (Illumina) as recommended by the manufacturer and then sequenced by Illumina MiSeq (Illumina, San Diego, CA) technology at the Center for Genomics and Bioinformatics (CeGenBio) of the Drug Research and Development Center (NPDM) at the Federal University of Ceará, Brazil. 
Obtained sequences from Illumina sequencing of the four metagenomic samples were trimmed for quality control (QC) using the FastQC software (Andrews 2010). Libraries from all samples had lowquality sequences removed according to the preprocessing tool Trimmomatic ( $v$ 0.36) (Bolger et al. 2014) to select high quality sequences and for the removal of OTUs shorter than $50 \mathrm{pb}$ or of low quality (Phred score <20). OTUs were assembled into contigs with the aid of metaSPAdes v3.10.1 (Nurk et al. 2017) and, in order to improve assembly to generate scaffolds and to fill gaps, Assembly Improvement v1.7.0 (Page et al. 2016) was used, having as input the assembly obtained in the previous stage with their respective trimmed OTUs. The Redundans (v0.12c) tool (Pryszcz and Gabaldón 2016) was used for final assembly of sequences, reducing fragmentation and eliminating redundant scaffolds.

The resulting four pooled datasets (RS, RA, RM and RG) were submitted to the MG-RAST (MetaGenome Rapid Annotation using Subsystem Technology, v3.1) server for annotation (http://metagenomics.nmpdr.org) (Meyer et al. 2008). Functional annotation of assembled contigs was performed using BLAST against the M5NR protein database and the pipeline mapped the uploaded high quality OTUs (unassembled) against the annotated contigs in order to create quantitative (abundance) profiles. Our DNA dataset is available on MG-RAST under the following MG-RAST ID: mgm4765758.3, mgm4765759.3, mgm4765760.3 and mgm4765761.3.

\section{Gene function classification}

To retrieve information about gene function of the taxonomic groups, genes were annotated with clusters of orthologous groups (COG), KEGG Orthology (KO), nonsupervised orthologous group (NOG) and subsystem database including RefSeq and Subsystems inside MG-RAST that compared the homology of functional genes against the database. The total DNA datasets at a maximum e-value cut-off was of 1010 , with a minimum percent identity cut-off of $60 \%$ and a minimum alignment length cut-off of 15 base pairs (Pfister et al. 2010).

Material and methods were performed according to (Xavier et al. 2019).

\section{Results And Discussion}

\section{Quantification of heavy metals of soil samples}

Little is known about the profiles of microbial community composition and structure in these metal contaminated soils. Since a small number of eukaryotes have been investigated with respect to heavy metal resistance so far, the present work presents a solid investigation on the microbial communities from soils contaminated by heavy metal. As part of this investigation, it was carried out the quantification of the metals contained in the samples analyzed, in order to robustly relate the presence of gene sequences and heavy metal contamination. The results are disposed in Table 1.

The genus Aspergillus and Neosartorya have already been found in heavy-metal polluted environments in previous researches. In 2016, Khamesy and co-workers identified two isolates from Aspergillus genus that 
were able to tolerate the presence of high concentrations of lead and cadmium, between 0 to $2500 \mathrm{mg} \mathrm{L}^{-1}$ in waste deposits. According to Qayyum and co-workers (2016), three strains related to genera Aspergillus and one related to genera Neosartarya were found to be heavy metal resistants. These strains were isolated from sites under a slag heap at the Smelting Industry located in Weifang city, Shandong Province, China. In this work, the authors showed that the fungal isolates tested were able to grow in Sabouraud Dextrose Agar medium containing 50 and $100 \mathrm{mg} \cdot \mathrm{L}^{-1}$ of lead and chromium.

According to Vale et al. (2011), an Aspergillus niger strain was able to develop in culture medium supplied with growing concentrations of $\mathrm{Zn}$ and $\mathrm{Cr}$ until $100 \mathrm{mg}$. $\mathrm{L}^{-1}$. Authors found that ion $\mathrm{Cr}$ showed higher toxicity than ion $\mathrm{Zn}$, inhibiting the capacity of the fungus to develop during the germinative phase. Zinc ions showed to be beneficial to the biological membranes and required for the growth of microorganisms, however at high concentrations may be inhibitory or toxic to growth.

The RG and RM samples presented the highest abundance of OTUs given the large amount of organic carbon found in these samples (Table 1). Similarly, a high concentration of nitrogen could be observed in the RM sample. These soil compositions may have influenced the microbial community bioadsorption among the studied samples.

\section{In silico data analysis and assembly of sequences}

After quality control performed by FastQC software, the metagenomes sequenced by Illumina MiSeq plataform yielded approximately 674 thousand high-quality short DNA sequences. Annotation was performed using MG-RAST for taxonomic affiliation and putative protein-coding sequences related to heavy metal metabolism were searched against the databases including COG, KEGG Orthology and NOG. Principal properties of metagenomes, analysis statistics and the total of significant BLAST OTUs obtained are showed in Table 2.

\section{Taxonomic classification and heavy metal functional affiliation of fungi sequences}

High fungal abundance was found in all samples, totalizing 2.583 OTUs (10.5\%) from Ascomycota and 273 OTUs (1.1\%) from Basidiomycota phylum. However, low sequences from Mortierellomycotina (RM 4 OTUs; RG - 8 OTUs) and from Entomophthoromycotina (RG - 3 OTUs; RM - 1 OTU) subphyla were found. Among the four samples, the greater fungal abundance was revealed in RG site, i.e., the less contaminated sampled spot, with 964 and 116 sequences from Ascomycota and Basidiomycota, respectively. Within RA sample, 759 sequences related to Ascomycota and 56 assigned to Basidiomycota phylum were found, representing the second most abundant site sampled. The RM sample, highly contaminated with heavy metals, presented 716 and 65 Ascomycota and Basidiomycota related sequences, respectively. From RS sample, 144 and 36 OTUs from Ascomycota and Basidiomycota were recovered, respectively (Figure 2 and Table 3 ).

The great fungal diversity was verified by the presence of representatives of 12 orders including Capnodiales, Pleosporales, Eurotiales, Onygenales, Helotiales, Pezizales, Saccharomycetales, 
Schizosaccharomycetales, Hypocreales, Magnaporthales, Phyllachorales and one unclassified taxonomic group from the phylum Ascomycota, suggesting a new sequence yet to be classified. On the other hand, five orders belonging to the phylum Basidiomycota were found: Agaricales, Polyporales, Malasseziales, Tremellales and Ustilaginales. One (Mortierellales) and two (Entomophthorales and Mucorales) orders were found from Mortierellomycotina and Entomophthoromycotina subphyla, respectively. Blastocladiales order was found from Bastocladiomycota phylum and Chytridiomycota phylum was represented by Cladochytriales, Chytridiales, Spizellomycetales and Monoblepharidales orders (Figure 2 and Table 3).

The majority of Ascomycota OTUs in all samples were related to the classes Eurotiomycetes (910 OTUs) and Sordariomycetes (1.030 OTUs) (Figure 3). From Eurotiomycetes class, the order Eurotiales was the most diverse, containing 238, 75, 282, 98 and 41 sequences from genera Aspergillus, Emericella, Neosartorya, Penicillium and Talaromyces, respectively (Table 3). The greatest diversity was found in GR sample (control), showing that the absence of heavy metals preserves the characteristics of the environment, allowing the development of different classes of these microorganisms, thus increasing fungal diversity. The sample RS, highly contaminated with heavy metals, presented the lowest microbial diversity belonging to these two classes, revealing that the presence of such substances have undermined the survival and/or the development of some classes which were not able to adapt to the contaminated environment. Presence of species belonging to Eurotiales order, such as Penicillium and Aspergillus, in sites contaminated with heavy metals, occurs due to the ability of individuals of these species to remove heavy metals from the environment, such as chromium and nickel (Iram et al. 2012)

From Sordariomycetes class, the orders Sordariales and Hypocleales were the most abundant, mainly within RA (higher Sordariales sequences OTUs) and RG samples (higher Hypocreales sequences OTUs) (Figure 4 and Table 3). In total, 334 sequences related to Hypocreales and 552 related to Sordoriales orders were found. From Sordariales order, sequences OTUs from genera Chaetomium (184 OTUs), Neurospora (222 OTUs), Bombardia (2 OTUs) and Podospora (144 OTUs) were found. Concerning to Hypocreales order, sequences OTUs belonged to the genera Gibberella (238 OTUs), Nectria (92 OTUs), Cordyceps (1 OTU) and Hypocrea (3 OTUs) (Table 3). At class level, Eurotiomycetes and Sordariomycetes were the most abundant taxonomic groups within Ascomycota phylum (Figure 2). Sequences retrieved from sample RA belonged to genera Chaetomium (115 OTUs), Bombardia (2 OTUs), Neurospora (110 OTUs), and Podospora (77 OTUs), same genera recovered (except Bombardia genus) from RG sample sequences which, however, were less abundant, with 27 sequences OTUs from Chaetomium, 63 from Neurospora and 32 from Podospora. In these two locations, the higher frequencies of sequences OTUs related to those genera are possibly due to the lower concentration of heavy metals, which allowed these microbial communities to thrive. Considering that it was possible to observe a reduction in the number of sequences related to the same genera found in the samples contaminated with greater concentration of heavy metals (RS and RM), it is possible to infer that the presence of these contaminants interfered in the homeostasis of the environments, culminating in the reduction of these microbial communities. 
A considerable number of OTUs related to Saccharomycetes class was observed in all samples sites, reaching 54, 43, 57 and 52 OTUs from RM, RS, RG and RA, respectively (Table 3). Yeasts have robust strategies of resistance to heavy metals including mechanisms that lead to the detoxification of the cytoplasm, exerted by transporting the metals to the outside of the cell by specific carriers, or by accumulation of metals, normally complexed with thiolated peptides, in organelles such as vacuoles (Fidalgo 2011; Tsai et al. 2009). In addition, the composition of sampling site, composed by $30.16 \mathrm{~g} . \mathrm{Kg}^{-1}$ of total organic carbon (data not shown), provided a large amount of nutrients for the development of Saccharomycetes and other filamentous fungi.On the other hand, very low unclassified OTUs related to Ascomycota were found in RG sample (control) (Figure 3), showing that the contamination by heavy metals can affect the composition of any microbial community.

The higher Basidiomycota abundance found in this work was related to the Agaricomycetes class derived from samples RA, RG, RM and RS, totalizing 26, 53, 37 and 18 OTUs, respectively (Figure 5). Again, the majority of sequences OTUs from these groups were recovered from RG sample (control), the less heavy metal contaminated site (data shown on Table 1). The orders Agaricales and Tremellales were the most abundant taxonomic groups, with 122 and 67 OTUs respectively. Agaricales order was represented by sequences of Coprinopsis (38 OTUs), Moniliophthora(14 OTUs), Schizophyllum (26 OTUs) and Laccaria (44 OTUs) genera. Concerning Tremellales, only sequences from Filobasidiella genus were found (65 OTUs). Sequences related to Blastocladiomycota and Chytridiomycota phyla were found from samples RM, RG and RA. Chytridiomycota was represented by sequences from genera Cladochytrium (2 OTUs), Olpidium(1 OTU), Spizellomyces (4 OTUs) and Harpochytrium (2 OTUs), while Blastocladiomycota was represented by sequences from Allomyces (2 OTUs) and Blastocladiella (1 OTUs) genera (Table 3). These two last phyla were not represented by any sequence of RS sample, problaby due to the great contamination of all heavy metals, mainly $\mathrm{Cr}, \mathrm{Pb}$ and $\mathrm{Zn}$. However, as the other contaminated sites presented sequences from Chytridiomycota and Blastocladiomycota phyla, it is possible to affirm that these taxonomic groups are capable of thrive under certain concentrations of heavy metals, but can not tolerate high concentrations of lead specifically.

The fungi classified in the phyla Blastocladiomycota and Chytridiomycota present as similarity the production of spores with a single smooth flagellum. Some representatives of these phyla are cosmopolitan found in different ecosystems and terrestrial ecosystems (Jerônimo et al. 2015). The knowledge about tolerance to heavy metals by genus from Blastocladiomycota and Chytridiomycota phyla is very poor. In the work made by Jia and co-workers (2018) representantives from Chytridiomycota phyla were not affected by the presence of heavy metals $\mathrm{Cd}\left(5.27 \mathrm{mg} \cdot \mathrm{kg}^{-1}\right)$ and $\mathrm{Cu}\left(553.53 \mathrm{mg} \cdot \mathrm{kg}^{-1}\right)$. This could be related to the great amount of extracellular polymeric substances (EPS) that same fungi may produce by their metabolism. Georg and Gomes (2007), performed a study were the aquatic fungus Blastocladiella emersonii was submited to a global transcriptional response by using cDNA libraries. The author found genes related to cellular transport function during exposure to $50 \mu \mathrm{M} \mathrm{Cd}$.

The sequences from Entomophthorales and Mucorales orders from Entomophthoromycotina subphylum belonged to species from genera Basidiobolus (RM - 1 OTU) and Rhizopus (RG - 3 OTUs). Subphylum 
Mortierellomycotina was represented by sequences of Mortierella genus, being 9 OTUs from RG site and 4 OTUs from RM site (Table 3).

Filamentous fungi are known to be resistant to heavy metals due to their ability to detoxify these compounds by several mechanisms such as i) valence transformation; ii) active uptake; iii) impermeability and sequestration; iv) extra and intracellular precipitation; $v$ ) biosorption to cell wall; vi) transformation of metals; vii) defense mechanisms including immobilization of heavy metals using extracellular and intracellular chelating compounds and viii) presence of transporter systems for the uptake of essential metals in the cell membrane (Islam et al. 2008; Qayyum et al. 2016). In the Agaricomycete Paxillus involutus, the uptake of $\mathrm{Cd}$ is made by the slow carrier-mediated transport into the cell after a rapid binding to the cell wall. The uptake partially depends on the membrane potential and it is linked to the transport of calcium (Baldrian 2003). Only one OTU from metagenomic sample RA related to environmental processes by signal transduction from calcium signaling pathway was found. Ahmad et al. (2005) evaluated an Aspergillus sp. strain for the biosorption potential of $\mathrm{Cr}$ and $\mathrm{Cd}$ and observed that bioadsorption of these metals ranged from $6.20-9.5 \mathrm{mg} \cdot \mathrm{g}^{-1}$ for $\mathrm{Cr}$ and $2.3-8.21 \mathrm{mg} . \mathrm{g}$ ${ }^{1}$ for Cd. According to the authors, results revealed that fungi from metal polluted sites showed higher metal tolerance and bioadsorption capacities. In white-rot fungi, the heavy metals are intracellularly chelated by peptidic low molecular weight compounds phytochelatins or metallothioneins. In the environment, heavy metals can interact with extracellular enzymes of fungi and must be taken up by the fungus to promote a physiological response Baldrian (2003). According to Cui et al. (2017), the Mortierella sp. species showed not only the potential to effectively reduce the heavy metal activities of $\mathrm{Zn}, \mathrm{Pb}$ and $\mathrm{Mn}$ up to 74,85 and $79 \%$, respectively from mine tailings, but also significantly shorten the remediation period of the environment with a consequent improvement in the site living conditions.

According to Colwell and Coddington (1994), species accumulation curves plot the cumulative number of species recorded as a function of sampling and effort, showing the rate at which new species are found. Thus, statistical analyzes from the data set with complete coverage is expected to result in a plateau shaped curve (Oliveira et al. 2011). In this work, the fungal communities from all analyzed samples exhibited similar relative species richness in accordance with the rarefaction curves, and the profile of these curves suggests that the sampling was able to cover the fungal diversity of these samples (Figure $6)$.

Alpha diversity (a) is the total number of species in a habitat (Nogueira et al. 2008; Magurran 2004). In our work, a great species richness (alpha diversity) was found in all samples. The diversity found in RG sample totalized 68 distinct species ( 55 from Ascomycota, 8 from Basidiomycota, 2 from Chytridiomycota, 1 from Blastocladiomycota, 1 from Entomophthoromycota and 1 from Mortierellomycota), followed by RM sample, which recovered 68 species $(52,8,4,1,1$ and 2 from Ascomycota, Basidiomycota, Chytridiomycota, Blastocladiomycota, Entomophthoromycota and Mortierellomycota, respectively). Samples RA and RS recovered, respectively, 50 and 40 distinct species of Ascomycota, and 8 Basidiomycota species each. Only RA sample was able to recovered 3 species from Chytridiomycota (Table 4). 
In general, the RS sample showed a considerable reduction (about 90\%) in the amount of genera representative of the Ascomycota phylum ( $n=57)$, mainly due to the presence of lead, chromium and zinc, when compared to the control sample $(n=559)$, followed by RA $(n=515)$ and RM $(n=489)$ with a reduction of $7.8 \%$ and $12.5 \%$, respectively. In the same way, the genera belonging to the phylum Basidiomycota also suffered a reduction in numbers, totaling RS ( $n=25 ; 66.2 \%)$, RA ( $n=40 ; 46 \%)$ and RM $(n=48 ; 35 \%)$ compared to the control $(n=74)$ (Table 3$)$.

Despite the higher contamination with $\mathrm{Cd}, \mathrm{Cu}, \mathrm{Ni}$ and $\mathrm{Zn}$ metals in the RM sample in comparison to $\mathrm{RS}$ sample, RS site presented lower a-diversity (48 distinct species), and, comparing the contaminations of all samples, the possible responsible for the lower diversity was the higher concentration of lead in this area (Table 1), as the presence of other heavy metals such as $\mathrm{Zn}$ and $\mathrm{Cr}$ did not interfere in the diversity of the other samples and lead is considered a non-essential and environmental micro-contaminant, being more harmful to the fungal communities (Rasool and Irum 2014; Woldeamanuale 2017). The total alphadiversity of, RM and RG samples had the same number of species recovered, while RA sample had only about $10 \%$ of the loss of alpha diversity (Table 4 ). These results may be explained by the difference in the number of OTUs related to some genera found in the four samples studied (Table 3). The genera that emphasize this find are Aspergillus and Chaetomium. In the RG sample, 87 sequences OTUs of Aspergillus and 27 of Chaetomium were found. Meanwhile, in the RM sample, were recovered about 25\% and $51 \%$ more sequences OTUs from Aspergillus and Chaetomium, respectively. These two genera may be acting as the main groups involved with the expression of genes related to heavy metal tolerance, since the other genera showed less number of OTUs recovered. In the same way, RA sample (moderate contamination of all heavy metals), was able to recovered about 3.5 times more OTUs of Chaetomium, 1.4 times more OTUs of Podospora andabout 74\% more OTUs of Neurospora, compared to RG sample. The number of sequences assigned to genus Neosartorya in RG and RM samples was practically the same (106 and 104, respectively), showing that the concentration of metals found within RM sample did not affect the prevalence of this group of organisms. From these results, it is possible to affirm that the genera Neurospora, Aspergillus, Podospora, Chaetomium and Neosartorya are tolerant to high levels of heavy metals.

The genera Neurospora and Aspergillus have been reported as heavy metal tolerant fungi (Iram et al. 2009; Joshi 2014; Oladipo et al. 2016; Qayyum et al. 2016). According to Haruma et al. (2018), the rootendophytic Chaetomium cupreum, which produced siderophores, enhanced aluminium stress tolerance in Miscanthus sinensis (a plant species) by accumulating aluminium in mycelia around the roots. Xu et al. (2015), performed a work were the diversity of dark septate endophytes and their cadmium tolerance were investigated from mine tailing soils that contained excessive $\mathrm{Pb}, \mathrm{Zn}$, and $\mathrm{Cd}$. In this work, strains of the genus Podospora were isolated from this environment. The Neosartorya genus were already found in heavy metal sediments, in a study conducted by Abdel-Azeen and coworkers (2015), in which this genus was isolated from Lake Manzala sediments, in Egypt, contaminated by industrial activity. Urík and coworkers (2010) verified the thallium ( $\mathrm{TI})$ metal bioabsorbability and bioremediation ability of this genus and, in 2016, Onn et al. isolated endophytic fungi from mangrove plants and soil and verified that an isolate of Neosartorya sp. showed maximum $\mathrm{Cu}$ and Zn biosorption ability. 
According to Kacprzak and Malina (2005) the genus Mortierellawas most frequently present in soil with high contents of metals including zinc and iron, although, it did not occur in non-contaminated soil samples. On the other hand, the genus Basidiobolus probably has not yet been described as being a genus of fungus resistant to heavy metals.

Concerning Entomophthoromycotina and Mortierellomycotina subphyla, similar results were found as the number of sequences assigned to these taxonomic groups were higher in the RG sample (11 OTUs) in comparison to the RM sample, which showed 4 representatives from the Mortierellales order (Mortierella genus - data not shown) and 1 sequence OTU assigned to Entomophthorales orders (Basidiobolus genus - data not shown). Interestingly, Entomophthorales order was only found in a contaminanted site (RM), and as there is no information available in the literature associating these organisms to heavy metal contamination, this finding shows the promising capability of this group for future studies. Concerning the Mucorales, sequences assigned to this group were only found in the less contaminated site (RG), showing the sensitivity of these organisms to heavy metal contamination. No sequences of Entomophthorales and Mucorales were found in the RS sample, the site with the highest lead contamination. Regarding Blastocladiomycota and Chytridiomycota subphyla, no sequences assingned to these two groups were found within RS sample, showing that lead contamination may have been the most striking for the survival of these organisms in the environment. However, members of Chytridiomycota subphylum, i.e.Cladochytridium, Olpidium and Harpochytrium, were only found in RM sample, considered highly contaminated. There is no available information about Cladochytrium and Harpochytrium heavy metal resistance in the literature. Olpidium zoospores were killed under the presence of high concentration of copper and zinc in a study conducted by Tomlinson and Faithfull (1979), however the effects of heavy metals in other zoosporic fungi remains poorly studied (Gleason et al. 2010).

\section{Fungal taxonomic affiliation of heavy metal metabolism and tolerance and biodegradation}

With respect to tolerance, functional metabolism and biogradation of heavy metals, analyzes of the Ascomycota sequences of the four samples utilizing the KO (KEGG Orthology) database revealed a high number of sequences OTUs related to genes responsible for the metabolic pathways of the target compounds, with a total of 635 OTUs, being 161, 264, 157 and 53 sequences from RA, RG, RM and RS, respectively. The sequences were shown to be associated mainly to Metabolism (307 OTUs) and Genetic Information Processing (174 OTUs), followed by Cellular Processes (67 OTUs), Human Diseases (68 OTUs), Environmental Information Processing (23 OTUs) and Organismal Systems (6 OTUs) gene (Figure 7A). In the Basidiomycota sequences analyzes, positive OTUs related to Metabolism (17 OTUs) and Genetic Information Processing (12 OTUs) functions were found within all samples (Figure 6B). Functional analyzes performed by COG database revealed one OTU related to predicted divalent heavymetal cations transporter and one OTU related to copper chaperone in RA sample. The copper chapenone is a metalloprotein responsible for the delivery of $\mathrm{Cu}$ to Superoxide dismutase that constitutes a very important antioxidant defense against oxidative stress (Younus 2018). According to Zhang et al. (2016) heavy metals such as lead- and cadmium- caused chemical stress and reactive oxygen species formation 
in Phanerochaete chrysosporium, a species from the Basidiomycota phylum. The authors reported the lead-and cadmium - induced oxidative stress on the activities of catalase enzyme. In the same way, in your study, were found same OTUs related to predicted Zn-dependent proteases (2 OTUs), predicted Zndependent hydrolases of the beta-lactamase fold (3 OTUs), predicted metal-dependent protease of the PAD1/JAB1 superfamily (2 OTUs) and cytosine deaminase and related metal-dependent hydrolases (2 OTUs), data suggesting the use of heavy metals for cellular activity. The results, especially from COG database, showed the recovery of a large amount of potential unknown functional genes sequences. In addition, a large number of genes sequences associated with basal metabolism were retrieved from all four samples, such as amino acid transport and metabolism, suggesting the presence of a powerful metabolic energy in the environment highly contaminated with heavy metal, which allows the maintenance of the basic microbial activities.

Sequences associated with DNA repair genes and affiliated to Ascomycota phylum were retrieved within three samples, including two contaminated with heavy metals (RA and RS), totalizing 12 OTUs (Table 5). In the RM sample, the most contaminated with metals, no DNA repair genes were found, contrary to what was expected, since the presence of heavy metals such as chromium and cadmium may activate stressresponsive pathways in yeasts and filamentous fungi (Pócsi 2011; Viti et al. 2014). However, the sample presented the higher number of genes related to heavy metals biosorption processes, which shows that the biosorption is the main tolerance activity executed by the fungal community inhabiting this site. The RA site, moderately contaminated with heavy metals, presented both DNA repair genes and genes related to heavy metals biosorption processes, which indicates that fungal communities inhabiting this site have developed different adaptation mechanisms to confront the contamination. No sequences related to genes associated to repair of DNA and membrane transport processes assigned to Basidiomycota, Mortierellomycotina and Bastocladiomycota phyla and Entomophthoromycotina and Mortierellomycotina subphyla were found. Thus, must probably, the fungal sequences assingned to these taxonomic groups may not have the capacity to maintain microbial cellular life and/or to biosorb the heavy metals present in these samples. On the other hand, a large number of fungal genera were found ( $R M=53$ OTUs, RS $=25$ OTUs and RA $=43$ ), suggesting the ability to tolerate the contamination heavy metal in each sample site.

The mechanism involved in the bioadsorption process can range from ion exchange to membrane diffusion that can be influenced by biomass (carbon) and solution chemistry (nitrogen source). Factors such as cell age, environmental and nutritional conditions interfere with the preference of living biomass in the bonds with metallic ions. To overcome the toxic effect of metals at high concentrations, dead biomass may be preferred in these bioadsorption processes (Ahmad et al. 2005). The biosorption capacity of several metals such as $\mathrm{Zn}, \mathrm{Ni}, \mathrm{Cd}, \mathrm{Cu}$, Co by filamentous fungi biomass has been reported. In addition, metal concentration as well as factors such as temperature and $\mathrm{pH}$ are known to influence the biosorption process (Ahmad et al. 2005).

$\mathrm{Cr}(\mathrm{VI})$ biosorption decreases as the $\mathrm{pH}$ of the solution increases. In this study, an experiment performed on membrane reactors, the authors showed that a large COD removal can be achieved at a pH of 7 to 8 
(Chen 2012). In our work, all samples had pH values above 8.0 (except the control) as well. , the microbial community could be adsorbing metals due to a relatively high $\mathrm{pH}$ range.

Another important point of the bioremediation of metals is regarding the presence of a high percentage of cell-wall material within fungal biomass, which increases the variety of functional groups involved in metal binding (Dhankhar and Hooda 2011). In this sense, it is possible to establish a relationship between the enzymes or proteins involved in membrane transport processes and the biosorption of heavy metals by filamentous fungi. In our work, were found in RM and/or RA samples, proteins sequences involved in signal transduction including two-component system (11 OTUs) and calcium signaling pathway (1 OTU) as well as proteins involved in membrane transport such a ABC transport (3 OTUs), endorsing the role of these proteins in the adaptation of filamentous fungi in contaminated environments. The properties of environments, especially those heavily contaminated with heavy metals from manufacturing industries of aluminum, leather dyeing and those that utilize toxic, corrosive and flammable products, may influence and modify the microbial community composition and functionality. By using metagenomic approach, it was demonstrated that the diversity and dynamics of metabolic activities in the microbial communities from banks of stream, conferring these communities the role of recyclers of circulating compounds and making the filamentous fungi a key point in the biosorption of heavy metals, resulting in the reduction of these compounds in the environment. The environment impacted with heavy metals is a drastically modified habitat, and the microbial communities must adapt to the new toxic conditions. Filamentous fungi has the ability to adjust throught the expression of genes involved to heavy metal bioremediation process, aiming to survive and proliferate in extremely toxics environments surrounding manufacturing industries that disposal toxic products including heavy metals. The results obtained from the metagenomic approach from this work provide valuable and robust information for subsequent studies focused on the development and improvement of selective culture media for the isolation of fungal strains adapted to bioremediation processes from environments contaminated with heavy metals.

\section{Conclusion}

In our work, metagenomics approaches was able to reveal a phylogenetic as well as metabolic profile of the fungal community associated with soil samples contaminated with heavy metals. The most abundant phyla were Ascomycota and Basidiomycota, known to be resistant to various environments due to their metabolic diversity. Howerer, sequences related to heavy metal metabolism were only found from Ascomycota phylum, demonstrating that the other phyla and subphyla found in all samples may have other mechanisms, genes or complex metabolic pathways for the processes of adaptation, metabolism and tolerance to heavy metals. From the Ascomycota phylum, the most abundant genera were Neosartorya, Aspergillus, Gibberella, Neurospora and Chaetomium. On the other hand, from Basisiomycota phylum, the genera Filobasidiella, Coprinopsis and Laccaria were the most abundant. The higher abundance of fungal sequences was encountered in the RG control sample, Rio Grangeiro, with 1,100 sequences ( $38 \%$ of all sequences), followed by RA sample (817 sequences - $28 \%$ ), RM sample (791-27\%) and, lowest abundance of sequences was found in RS sample, which contains the higher 
concentration of lead (180 sequences $-6 \%$ ). Concerning heavy metal metabolism, repair of DNA processes sequences were found in 3 of the 4 samples, not being present in the RM sample, considered the most contaminated site. Regarding heavy metals biosorption processes sequences, site RM recovered 8 sequences and site RA recovered 7 sequences. These gene sequences were not found in the control site (RG) nor within RS sample, the most contaminated with lead. It was possible to observe that the majority of fungal communities present in sites contaminated with heavy metal were able to thrive except in the presence of high concentration of lead, the metal that most interfered in the abundance of fungal sequences among all the sites sampled. The present work provides relevant data about the dynamics of adaptation, survival and tolerance of fungal communities under stress caused by industrial waste, in addition to bringing references to allow to infer the functions of these organisms in the environment and their potential for bioremediation.

\section{Declarations}

\section{Acknowledgment}

We thank FUNCAP (Fundação Cearense de Apoio ao Desenvolvimento Científico e Tecnológico, Process number DCR-0024-01438.01.00/12) for their financial support. L. C. L. Verde was supported by the FUNCAP. We also thank to the CEGENBIO (Central de Genômica e Bioinformática do NPDM/UFC), by the genomic analysis.

\section{Compliance with ethical standards}

Conflict of interest The authors declare no conflict of interest.

\section{References}

1. Abdel_Azeen AM, El-Morsy EM, Nour El-Dein MM, Rashad HM (2015) Occurrence and diversity of mycobiota in heavy metal contaminated sediments of Mediterranean coastal lagoon El_Manzala, Egypt. Mycosphere 6: 228-240.

2. Aguiar JE, Marins RV, Almeida MD (2007) Comparação de metodologias de digestão de sedimentos marinhos para caracterização da geoquímica de metais-traço na plataforma continental Nordeste oriental brasileira. Geochimica brasiliensis 21:304-323.

3. Ahmad I, Zafar S, Ahmad F (2005) Heavy Metal Biosorption potential of Aspergillus and Rhizopus sp. isolated from Wastewater treated soil. J Appl Sci Environ Mgt 9:123 - 126.

4. Akhtar S, Mahmood-ul-Hassan M, Ahmad R, Suthor V, Yasin M (2013) Metal tolerance potential of filamentous fungi isolated from soils irrigated with untreated municipal efluente. Soil Environ 32:5562.

5. Andrews S (2010) FastQC: a quality control tool for high throughput sequence data. Available online at: http://www.bioinformatics.babraham.ac.uk/projects/fastqc. 
6. Baldrian P (2003) Interactions of heavy metals with white-rot fungi. Enzyme and Microbial Technology 32:78-91.

7. Barone R, De Santi C, Esposito FP, Tedesco P, Galati F, Visone M, Di Scala A, De Pascale D (2014) Metagenomics, a valuable tool for enzymes and bioactive compounds discovery. Front Mar Sci 04:16.

8. Beale DJ, Karpe AV, Jadhav S, Muster TH, Palombo EA (2015) Omics-based approaches and their use in the assessment of microbial-influenced corrosion of metals. Corrosion reviews 34: 1-14.

9. Bolger AM, Lohse M, Usadel B (2014) Trimmomatic: a flexible trimmer for Illumina sequence data. Bioinformatics 30:2114-20.

10. Chen, J. P. (2012). Decontamination of heavy metals: processes, mechanisms, and applications. CrC Press.

11. Colwell RK, Coddington JA (1994) Estimating terrestrial biodiversity through extrapolation. Philos T Roy Soc Lond B 345:101-118.

12. Cui $z$, Zhang $X$, Yang H, Sun $L$ (2017) Bioremediation of heavy metal pollution utilizing composite microbial agent of Mucor circinelloides, Actinomucorsp. and Mortierella sp. Journal of Environmental Chemical Engineering 5:3616-3621.

13. Costa PS, Reis MP, Ávila MP, Leite LR, de Araújo FMG, Salim ACM, Oliveira G, Barbosa F, ChartoneSouza E, Nascimento AMA (2015) Metagenome of a Microbial Community Inhabiting a Metal-Rich Tropical Stream Sediment. Plos One 10:1-21.

14. Dhankhar R, Hooda A (2011) Fungal biosorption - an alternative to meet the challenges of heavy metal pollution in aqueous solutions. Environmental Technology 32:467-491.

15. Donati ER (2018) Heavy Metals in the Environment: Microorganisms and Bioremediation. CrC Press.

16. Dopson M, Baker-Austin C, Koppineedi PR, Bond PL (2003) Growth in sulfidic mineral environments: metal resistance mechanisms in acidophilic micro-organisms. Microbiology 149:1959-1970.

17. Feng G, Xie T, Wang X, Bai J, Tang L, Zhao H, Wei W, Wang M, Zhao Y (2018) Metagenomic analysis of microbial community and function involved in cd-contaminated soil. BMC Microbiol 18:1-13.

18. Fidalgo CIA (2011) Heavy metal resistance in extremophilic yeasts: a molecular and physiological approach. Dissertation, Universidade de Lisboa.

19. Georg RC, Gomes SL (2007) Transcriptome Analysis in Response to Heat Shock and Cadmium in the Aquatic Fungus Blastocladiella emersonii. Eukaryotic Cell 6:1053-1062.

20. Gleason FH, Schmidt SK, Marano AV (2010) Can zoosporic true fungi grow or survive in extreme or stressful environments? Extremophiles 14:417-425.

21. Gube M (2016) 4 Fungal Molecular Response to Heavy Metal Stress. In: Hoffmeister D (eds) Biochemistry and Molecular Biology. The Mycota (A Comprehensive Treatise on Fungi as Experimental Systems for Basic and Applied Research), 3rd edn. Springer, Cham.

22. Haruma T, Yamaji K, Masuya H, Hanyu K (2018) Root endophytic Chaetomium cupreum promotes plant growth and detoxifies aluminum in Miscanthus sinensis Andersson growing at the acidic mine 
site. Plant Species Biol 33:109-122.

23. Hemme CL, Deng Y, Gentry TJ, Fields MW, Wu L, Barua S, Barry K, Tringe SG, Watson DB, He Z, Hazen TC, Tiedje JM, Rubin EM, Zhou J (2010) Metagenomic insights into evolution of a heavy metalcontaminated groundwater microbial community. The ISME Journal 4:660-672.

24. Hiraoka S, Yang CC, WaSaki W (2016) Metagenomics and Bioinformatics in Microbial Ecology: Current Status and Beyond. Microbes Environ 31:204-212.

25. Iram S, Ahmad I, Javed B, Yaqoob S, Akhtar K, Kazmi MR, Zaman BU (2009) Fungal tolerance to heavy metals. Pak J Bot 41:2583-2594.

26. Iram S, Parveen K, Usman J, Nasir K, Akhtar N, Arou S, Ahmad I (2012) Heavy metal tolerance of filamentous fungal strains isolated from soil irrigated with industrial wastewater. Biologija 58:107116.

27. Iskandar NL, Zainudin NAIM, Tan SG (2011) Tolerance and biosorption of copper (Cu) and lead (Pb) by filamentous fungi isolated from a freshwater ecosystem. Journal of Environmental Sciences 23:824-830.

28. Islam MS, Saha AK, Mosaddeque HQM, Amin MR, Islam MM (2008) In vitro studies on the reaction of fungi Trichoderma to different herbicides used in tea plantation. Int J Sustain Crop Prod 3:27-30.

29. Jerônimo GH, de Jesus AL, Marano AV, James TY, de Souza JI, Rocha SCO, Pires-Zottarelli CLA (2015) Diversidade de Blastocladiomycota e Chytridiomycota do Parque Estadual da Ilha do Cardoso, Cananéia, SP, Brasil. Hoehnea 42:135-163.

30. Jia T, Wang R, Fan X, Chai B (2018) A Comparative Study of Fungal Community Structure, Diversity and Richness between the Soil and the Phyllosphere of Native Grass Species in a Copper Tailings Dam in Shanxi Province, China. Appl Sci 8:1297. https://doi:10.3390/app8081297

31. Joshi BH (2014) Evaluation and characterization of heavy metal resistant fungi for their prospects in bioremediation. Journal of Environmental Research And Development 8:876-882.

32. Kacprzak M, Malina G (2005) The tolerance and Zn2+, Ba2+ and Fe3+ accumulation by Trichoderma atroviride and Mortierella exigua isolated from contaminated soil. Canadian Journal of Soil Science 85:283-290.

33. Khamesy SJ, Hamidian AH, Atghia O (2016) Identification of the fungi absorbing heavy metals isolated from waste deposits of zinc factories, Zanjan province, Iran. Mycologia Iranica 3:65-73.

34. Lehembre F, Doillon D, David E, Perotto S, Baude J, Foulon J, Harfouche L, Vallon L, Poulain J, Da silva C, Wincher P, Oger-Desfeux C, Richaud P, Colpaert JV, Chalot M, Fraissinet-Tachet L, Blaudez D, Marmeisse R (2013) Soil metatranscriptomics for mining eukaryotic heavy metal resistance genes. Environmental Microbiology 5:1-37.

35. Magurran AF (2004) Measuring Biological diversity. Blackwell, Oxford.

36. Meyer F, Paarman D, D’Souza M, Olson R, Glass EM, Kubal M, Paczian T, Rodriguez A, Stevens R, Wilke A, Wilkening J, Edwards RA (2008) The metagenomics RAST server-a public resource for the automatic phylogenetic and functional analysis of metagenomes. BMC Bioinformatics 9:386. 
37. Mosier AC, Miller CS, Frischkorn KR, Ohm RA, Li Z, LaButti K, Lapidus A, Lipzen A, Chen C, Johnson J, Lindquist EA, Pan C, Hettich RL, Grigoriev IV, Singer SW, Banfield JF (2016) Fungi Contribute Critical but Spatially Varying Roles in Nitrogen and Carbon Cycling in Acid Mine Drainage. Frontiers in Microbiology 7:1-18.

38. Nogueira IS, Nabout JC, Oliveira JE, Silva KD (2008) Diversidade (alfa, beta e gama) da comunidade fitoplanctônica de quatro lagos artificiais urbanos do município de Goiânia, GO. Hoehnea 35:219233.

39. Nurk S, Meleshko D, Korobeynikov A, Pevzner PA (2017) metaSPAdes: a new versatile metagenomic assembler. Genome Res 27:824-834.

40. Oladipo OG, Awotoye OO, Olayinka A, Ezeokoli OT, Maboeta MS, Bezuidenhout CC (2016) Heavy metal tolerance potential of Aspergillus strains isolated from mining sites. Biorem J20:287-297.

41. Oliveira VM, Lopes-Oliveira PF, Passarini MRZ, Menezes CBA, Oliveira WRC, Rocha AJ, Sette LD (2011) Molecular analysis of microbial diversity in corrosion samples from energy transmission towers. Biofouling 27:435 - 447.

42. Onn ML, Lim PT, Mujahid A, Proksch P, Müller M (2016) Initial screening of mangrove endophytic fungi for antimicrobial compounds and heavy metal biosorption potential. Sains Malaysiana 45:1063-1071.

43. Page AJ, De Silva N, Hunt M, Quail MA, Parkhill J, Harris SR, Otto TD, Keane JA (2016) Robust highthroughput prokaryote de novo assembly and improvement pipeline for Illumina data. Microb Genom. https://doi: 10.1099/mgen.0.000083.

44. Pfister CA, Meyer F, Antonopoulos DA (2010) Metagenomic profiling of a microbial assemblage associated with the California mussel: a node in networks of carbon and nitrogen cycling. PLoS One 5:e105180.

45. Pócsi I (2011) Toxic metal/metalloid tolerance in fungi - a biotechnology-oriented approach. In Banfalvi G (ed) Cellular effects of heavy metals. Springer; Dordrecht, pp 31-58.

46. Pryszcz LP, Gabaldón T (2016) Redundans: an assembly pipeline for highly heterozygous genomes. Nucleic Acids Res 44:e113.

47. Qayyum S, Khan I, Maqbool F, Zhao Y, Gu Q, Peng G (2016) Isolation and Characterization of Heavy Metal Resistant Fungal Isolates from Industrial Soil in China. Pakistan J Zool 48:1241-1247.

48. Rasool A, Irum S (2014) Toxic Metal Effect on Filamentous Fungi Isolated from the Contaminated Soil of Multan and Gujranwala. Journal of Bioresource Management 1:38-51.

49. Tomlinson JA, Faithfull EM (1979) Effects of fungicides andsurfactants on the zoospores of Olpidium brassicae. Ann Appl Biol 93:13-19.

50. Tsai SL, Singh S, Chen W (2009) Arsenic metabolism by microbes in nature and the impact on arsenic remediation. Curr Opin Biotechnol 20:659-667.

51. Urík M, Kramarová Z, S Ševc J, Černanský S, Kališ M, Medved J, Littera P, Kolenčik M, Gardosova K (2010) Biosorption and Bioaccumulation of Thallium(I) and Its Effect on Growth of Neosartorya fischery Strain. Polish Journal of Environmental Studies 19:457-460. 
52. USEPA, 1994. Method 3015, Microwave Assisted Acid Digestion of Aqueous Samples and Extracts. USEPA, Washington, DC.

53. Vale MS, Abreu KV, Gouveia ST, Leitão RC, Santaella ST (2011) Efeito da toxicidade de Cr (VI) e Zn (II) no crescimento do fungo filamentoso Aspergillus niger isolado de efluente industrial. Eng Sanit Ambient 16:237-244.

54. Viti C, Marchi E, Decorosi F, Giovannetti L (2014) Molecular mechanisms of $\mathrm{Cr}(\mathrm{VI})$ resistance in bacteria and fungi. FEMS microbiology reviews 38:633-659.

55. Woldeamanuale TB (2017) Isolation, Screening and Identification of Cadmium Tolerant Fungi and Their Removal Potential. J Forensic Sci Criminal Inves 5:555-656.

56. Xavier LC, Costa PES, Hissa DC, Melo VMM, Falcão RM, Balbino, VQ , Mendonça LAR, Lima MGS, Coutinho, HDM, Verde, LCL (2019) Evaluation of the microbial diversity and heavy metal resistance genes of a microbial community on contaminated environment. Applied Geochemistry 105:1-6.

57. Xu R, Li T, Cui H, Wang J, Yu X, Ding Y, Wang C, Yang Z, Zhao Z (2015) Diversity and characterization of Cd-tolerant dark septate endophytes (DSEs) associated with the roots of Nepal alder (Alnus nepalensis) in a metal mine tailing of southwest China. Applied Soil Ecology 93:1-18.

58. Yin H, Niu J, Ren Y, Cong J, Zhang X, Fan F, Xiao Y, Zhang X, Deng J, Xie M, He Z, Zhou J, Liang Y, Liu $X(2105)$ An integrated insight into the response of sedimentary microbial communities to heavy metal contamination. Scientific Reports 5:1-12.

59. Younus $\mathrm{H}$ (2018) Therapeutic potentials of superoxide dismutase. International Journal of Health Sciences 12:88-93.

60. Zhang X, Niu J, Liang Y, Liu X, Yin H (2016) Metagenome-scale analysis yields insights into the structure and function of microbial communities in a copper bioleaching heap. BMC Genetics 17:412.

61. Zhao D, Li T, Shen M, Wang J, Zhao Z (2015) Diverse strategies conferring extreme cadmium (Cd) tolerance in the dark septate endophyte (DSE), Exophiala pisciphila: evidence from RNA-seq data. Microbiol Res 170:27-35.

\section{Tables}

Due to technical limitations, table 1-5 is only available as a download in the Supplemental Files section.

\section{Figures}




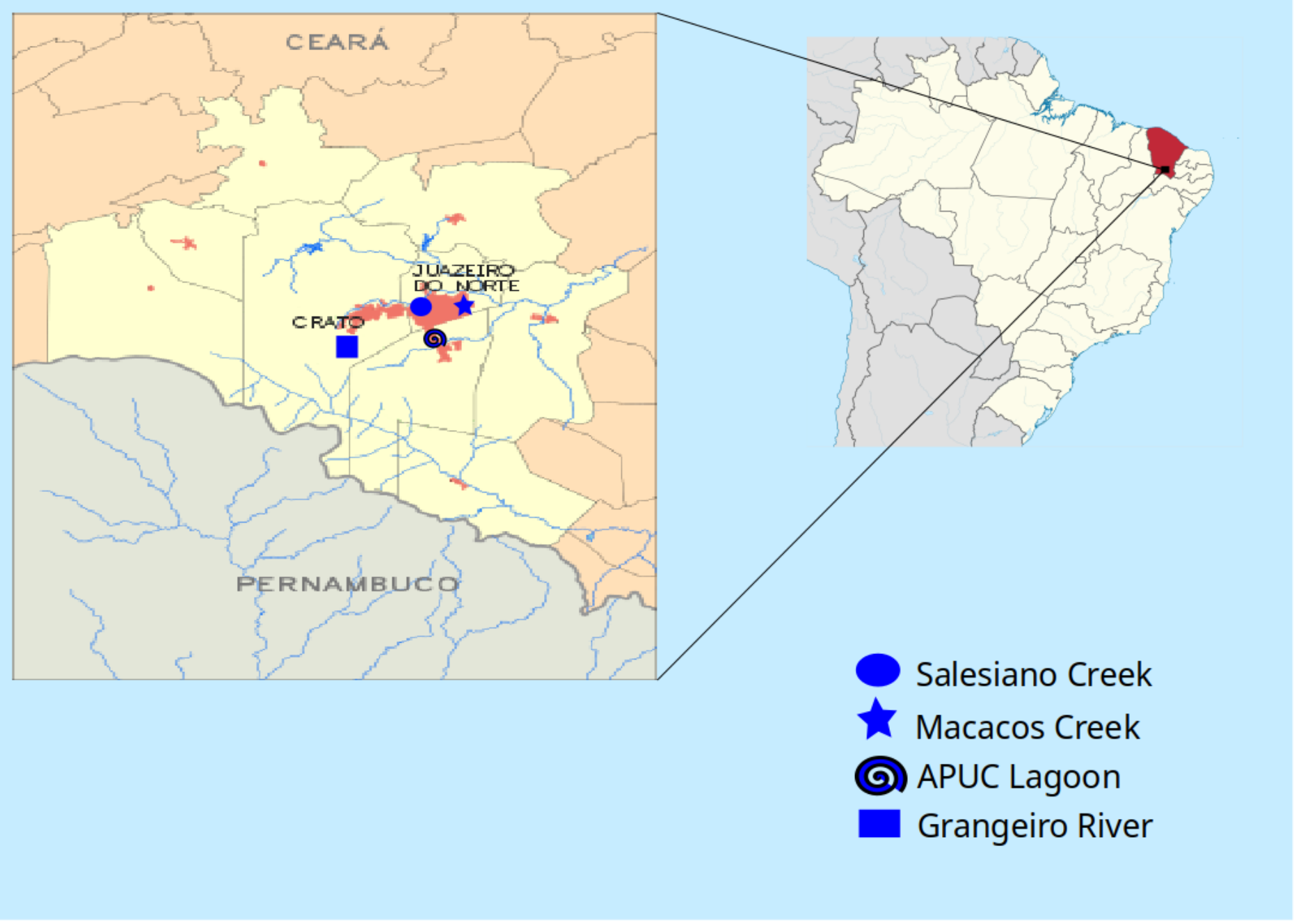

Figure 1

Sample collection 


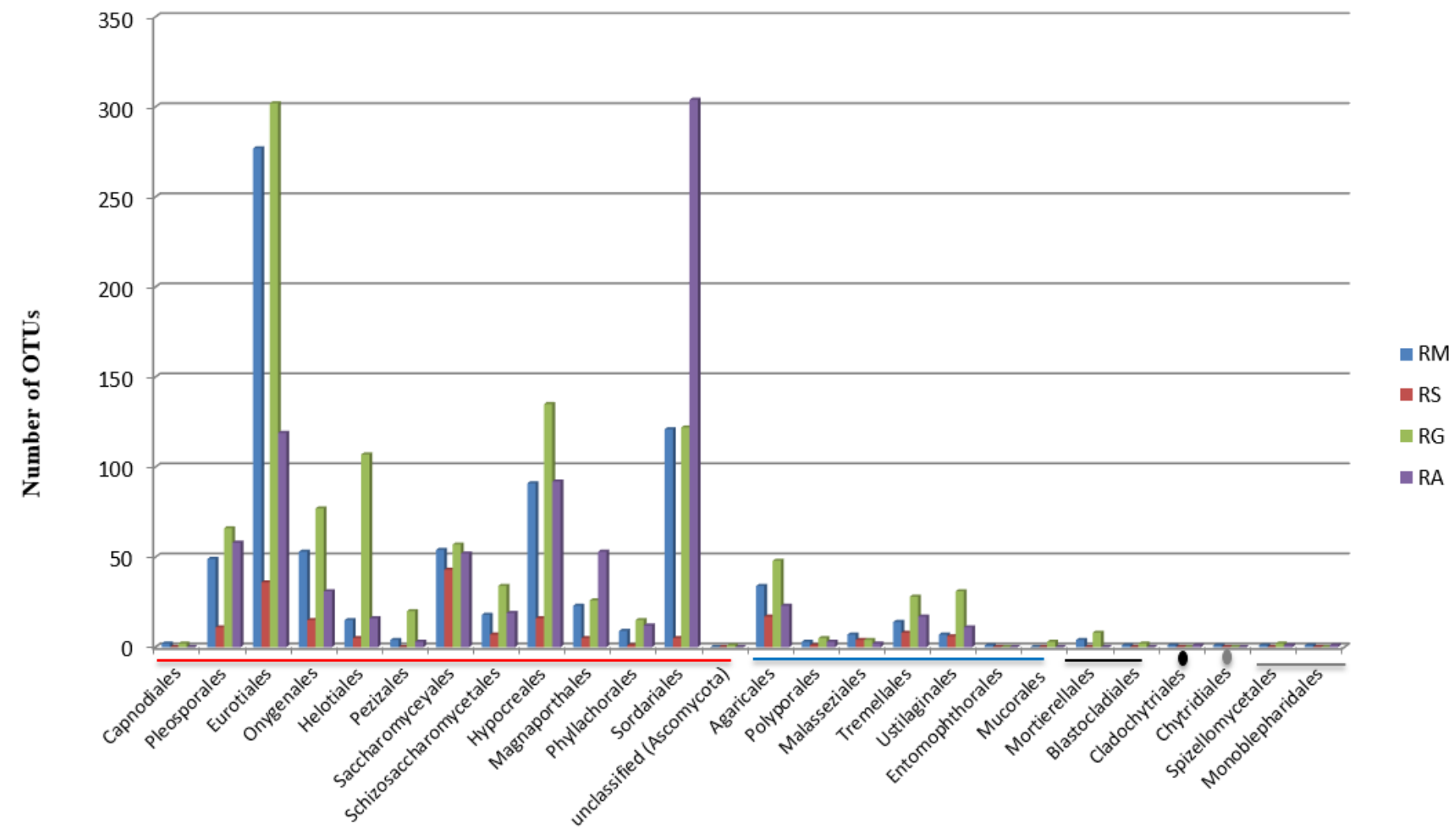

Figure 2

Taxonomic distribution of fungal orders present in all samples. The main groups of sequences are divided in bars below x-axis: Ascomycota (red bar), Basidiomycota (blue bar), Blastocladiomycota (grey point) and Chytridiomycota (grey bar) phyla; Entomophthoromycotina (black bar) and Mortierellomycotina (black point) subphyla. 

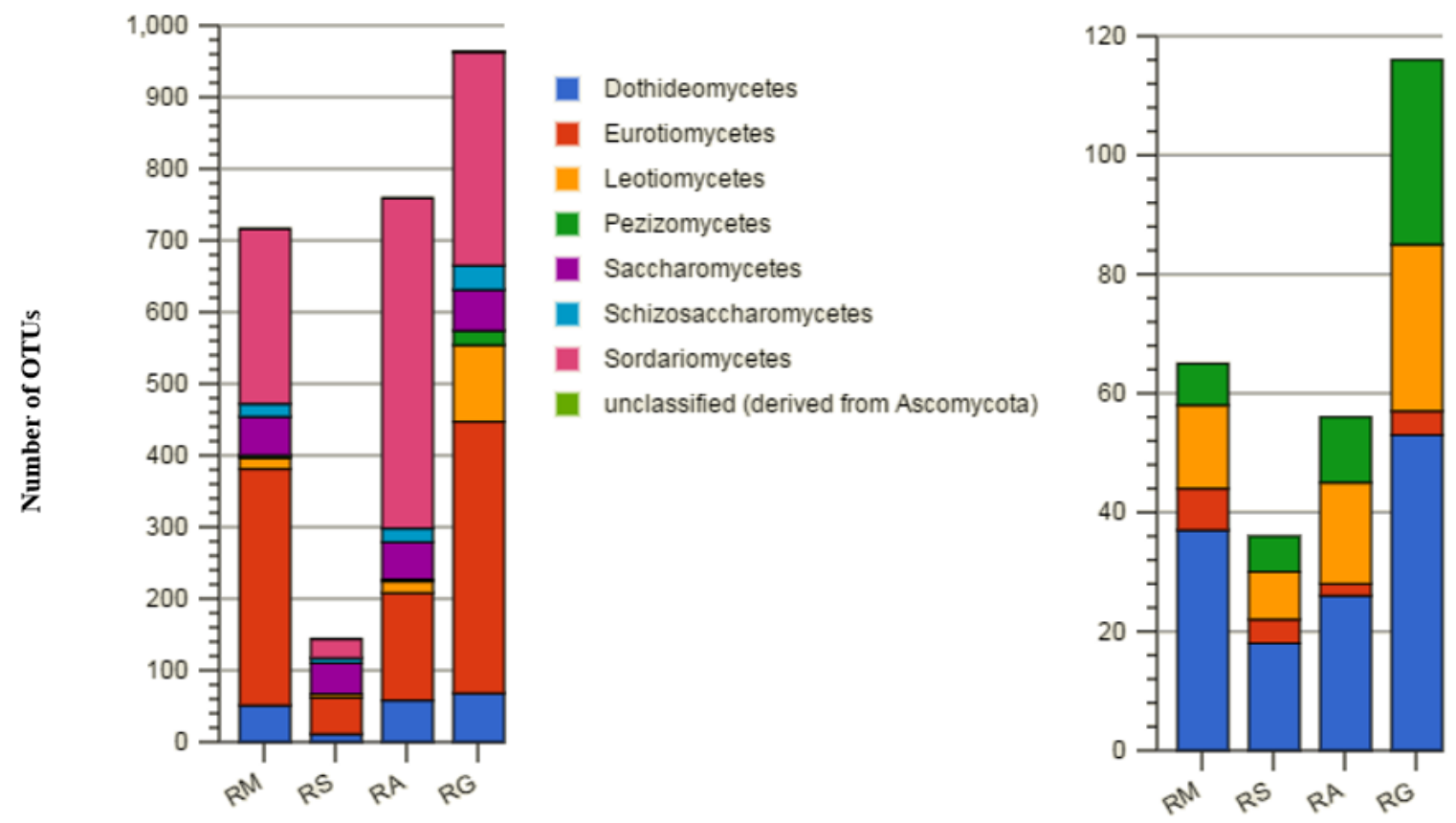

Agaricomycetes

Eurotiomycetes

II Leotiomycetes

- Pezizomycetes

- Saccharomycetes

- Schizosaccharomycetes

- Sordariomycetes

- unclassified (derived from Ascomycota)

Exobasidiomycetes

[1] Tremellomycetes

Ustilaginomycetes

\section{Figure 3}

Taxonomic distribution of different Ascomycota (A) and Basidiomycota (B) classes in four samples studied. 


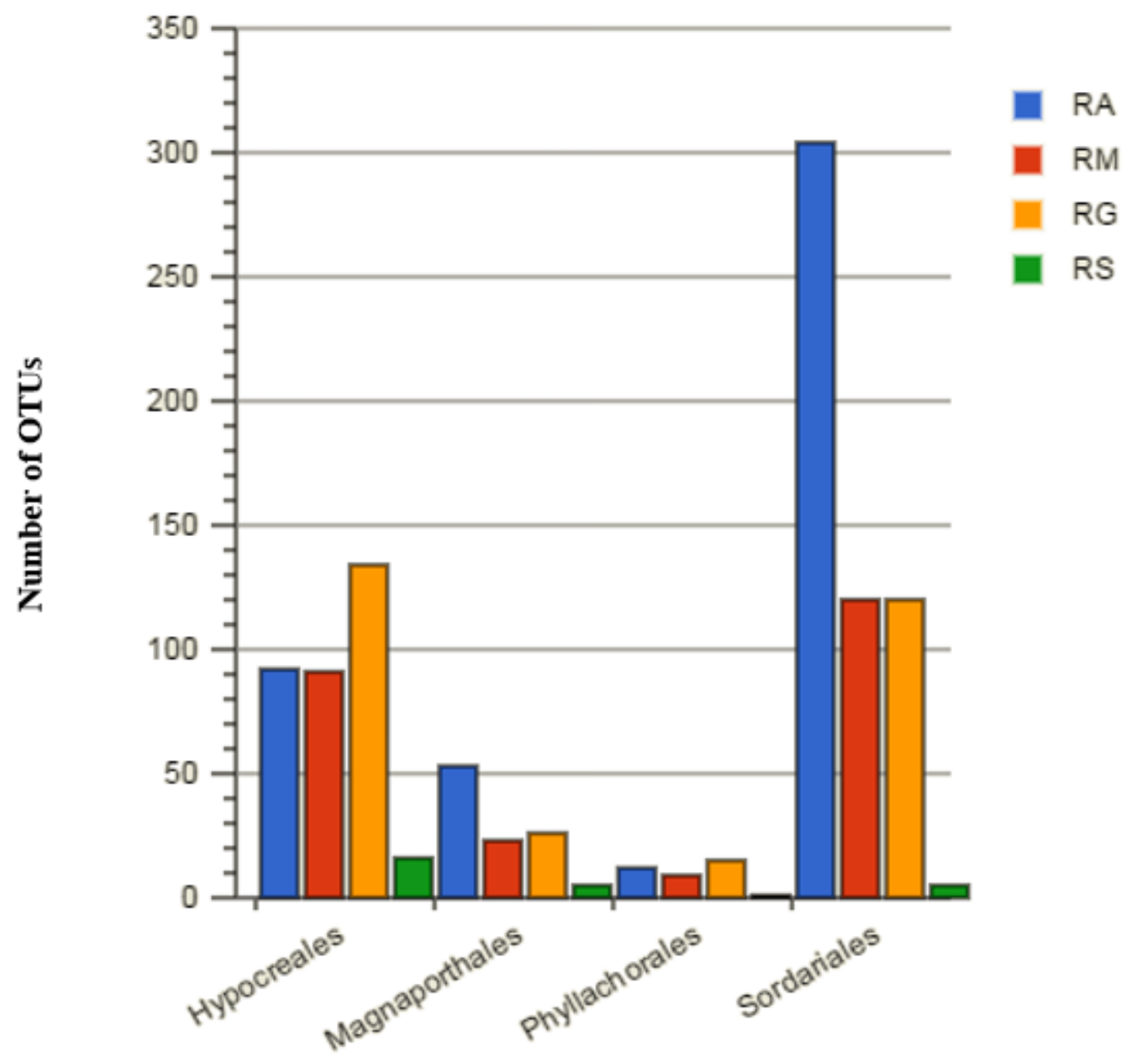

Figure 4

Abundance of orders belonging to Sordariomycetes class 


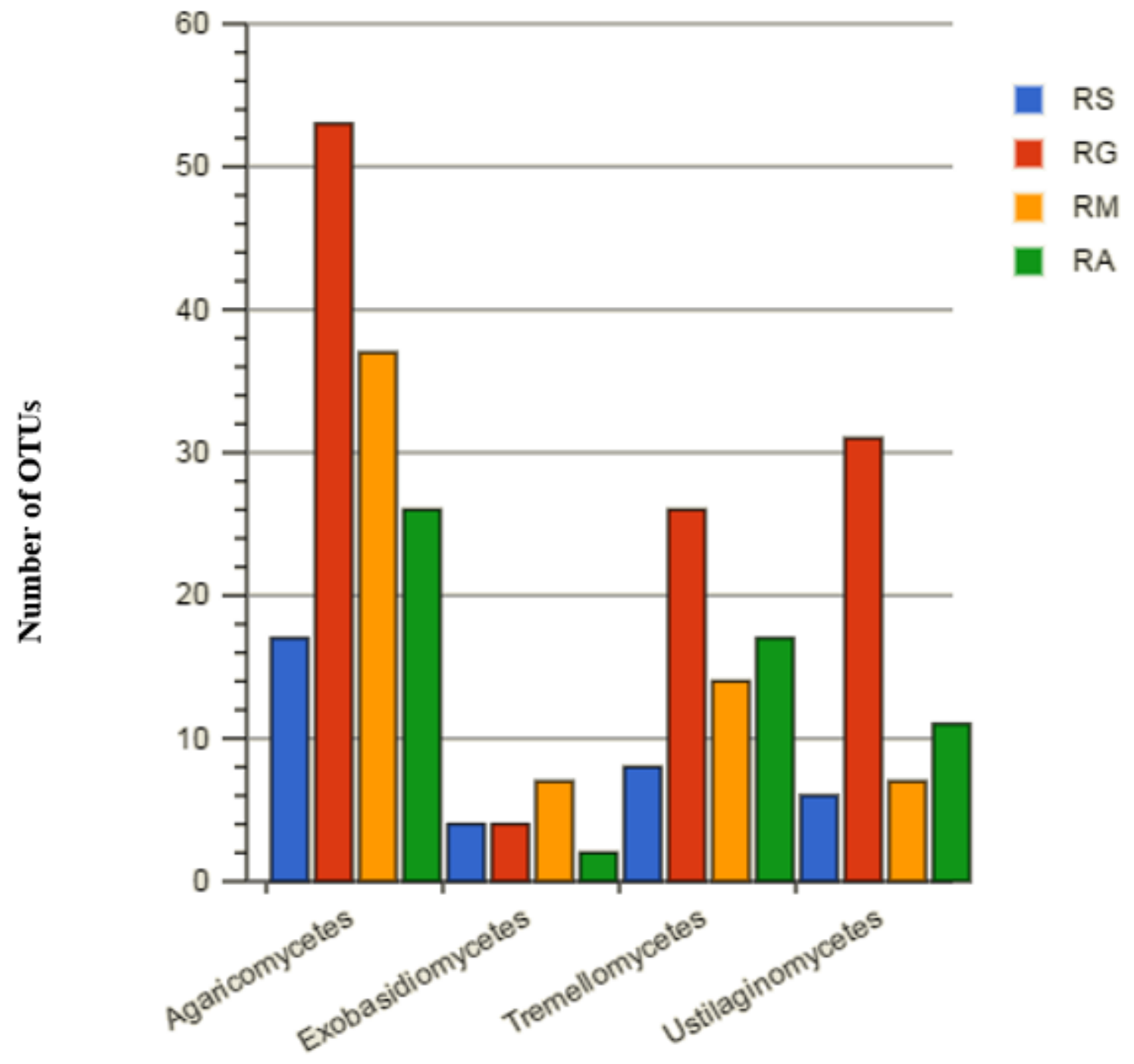

Figure 5

Taxonomic distribution of different Basidiomycota classes in four samples 


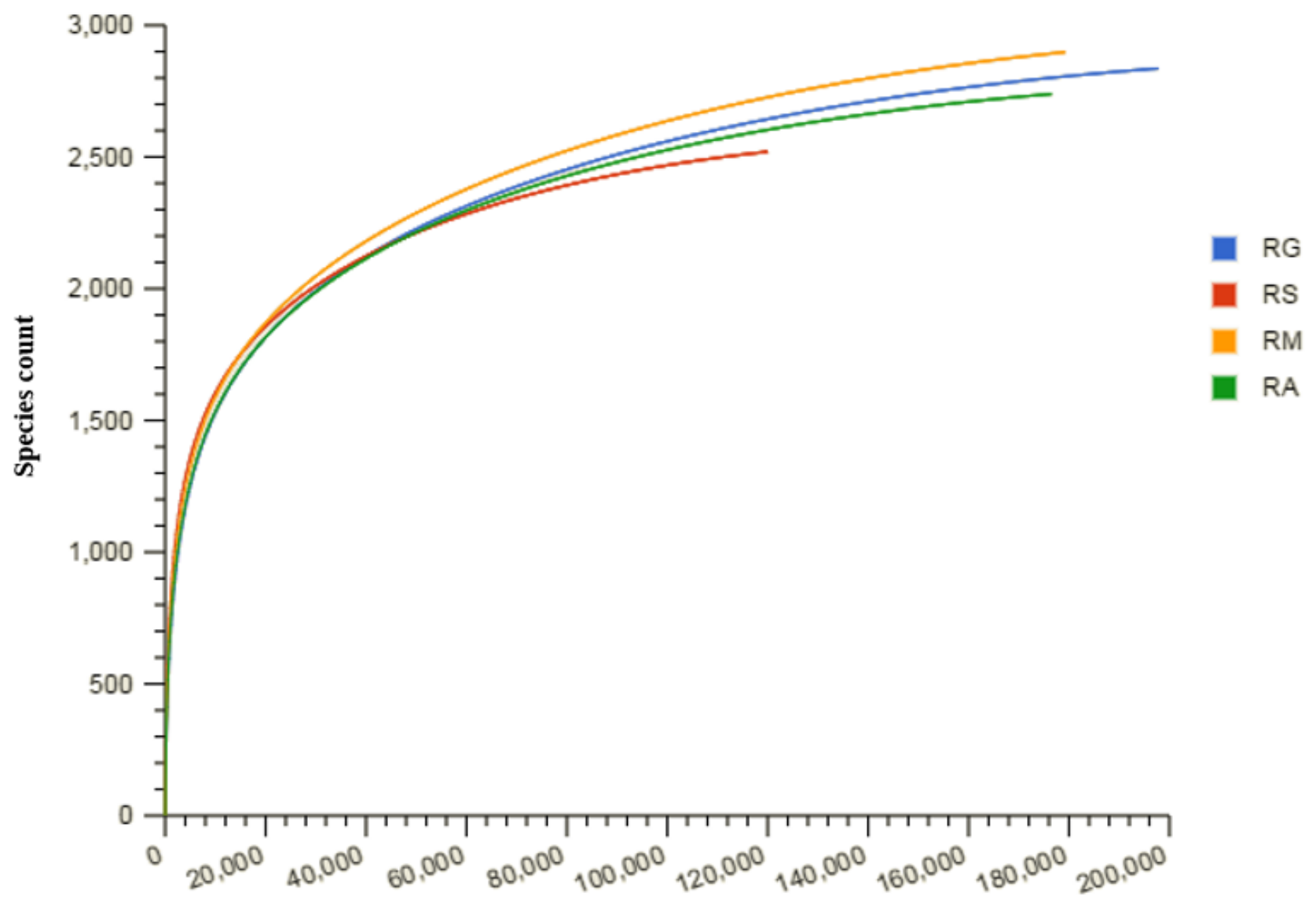

Figure 6

Rarefaction curves exhibit the recovered species richness from all samples. Evolutionary distance used was 0.03 .
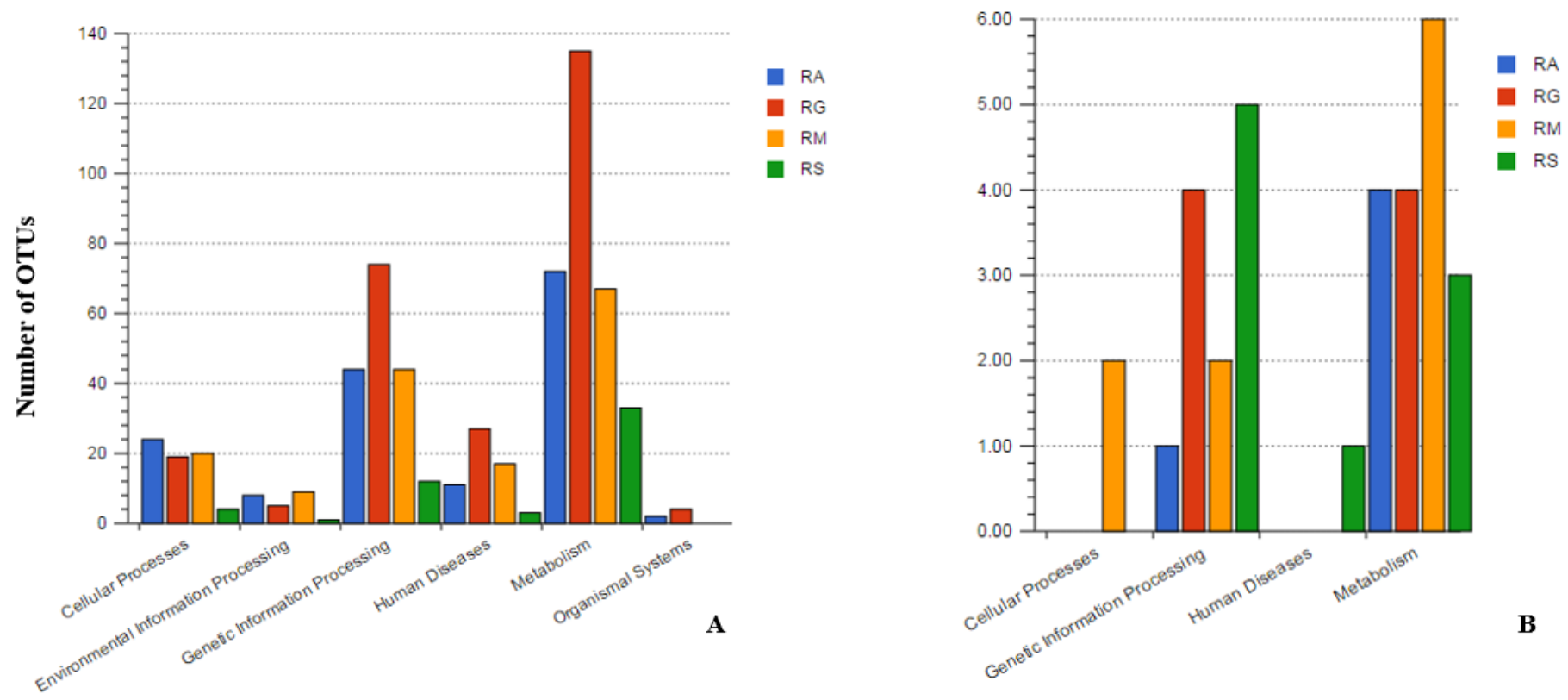
Figure 7

Ascomycota (A) and Basidiomycota (B) sequences related to heavy metals processing pathways, analyzed by $\mathrm{KO}$ database

\section{Supplementary Files}

This is a list of supplementary files associated with this preprint. Click to download.

- TABELASPassarinicorrecao.pdf 